Title

\title{
EXPERIMENTAL CONFIGURATION OF DIRECT DRIVE
CYLINDRICAL IMPLOSIONS ON THE OMEGA LASER
}

$$
\text { CONF-980605-- }
$$

Submitted to:

Author(s):

Cris W. Barnes, P-24

David L. Tubbs, X-TA

J. B. Beck, X-TA

N. M. Hoffman, X-CI

K. A. Klare, P-24

J. A. Oertel, P-24

R. G. Watt, P-24

T. R. Boehly, LLE, University of Rochester

D. K. Bradley, LLE, University of Rochester

J. P. Knauer, LLE, University of Rochester

12th Topical Conference on High Temperature Plasma

Diagnostics,

Princeton, NJ

June $7-11,1998$

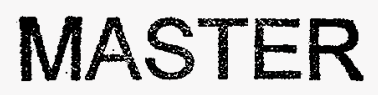

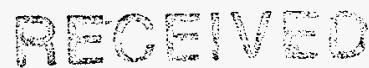

DEC 21938

DSTRIBUTION OF THIS DOCUAENT IS UHUHTED

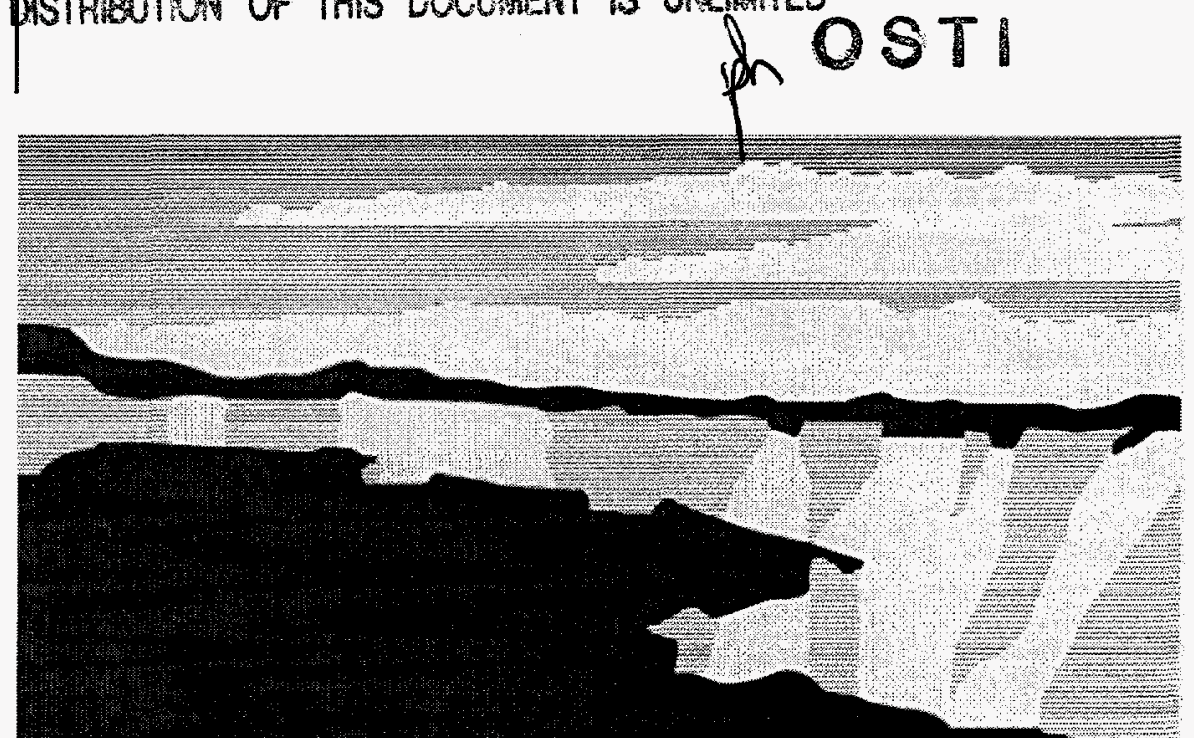

NATIONAL LABORATORY

Los Alamos National Laboratory, an affirmative action/ equal opportunity employer, is operated by the University of California for the U.S. Department of Energy under contract W-7405-ENG-36. By acceptance of this article, the publisher recognizes the the U.S. Government retains a nonexclusive, royalty-free license to puplish or reporduce the published form of this contribution, or to allow others to do so, for U.S. Government purposes. The Los Alamos National Laboratory requests that the publisher identify this article as work performed under the auspices of the U.S. Department of energy. 


\section{DISCLAIMER}

This report was prepared as an account of work sponsored by an agency of the United States Government. Neither the United States Government nor any agency thereof, nor any of their employees, makes any warranty, express or implied, or assumes any legal liability of responsibility for the accuracy, completeness, or usefulness of any information, apparatus, product, or process disclosed, or represents that its use would not infringe privately owned rights. Reference berein to any specific commercial product, process, or service by trade name, trademark, imanufacturer, or otherwise does not necessarily constitute or imply its endorsement, recommendation, or favoring by the United States Governmeat or any agency thereof. The views and opinions of authors expressed herein do not necessarily state or reflect those of the United States Governmeat or any agency thereof. 


\section{DISCLAIMER}

Portions of this document may be illegible in electronic image products. Images are produced from the best available original document. 
June 4, 1998

Contributed paper for 12th Topical Conference on

High-Temperature Plasma Diagnostics

Submitted to Review of Scientific Instruments

\section{Experimental Configuration of Direct Drive Cylindrical Implosions on the OMEGA Laser}

\section{Cris W. Barnes, David L. Tubbs, J. B. Beck, N. M. Hoffman, K. A. Klare, J. A. Oertel, R. G. Watt Los Alamos National Laboratory, Los Alamos, NM \\ T. R. Boehly, D. K. Bradley, and J. P. Knauer \\ Laboratory for Laser Energetics, University of Rochester, Rochester, $\mathrm{NY}$}

\section{ABSTRACT}

Details about the cylindrical implosions using direct-drive irradiation on the OMEGA Laser facility are provided. The experimental configuration, including orientation, construction, and mounting of the targets is described. An attempt to characterize the modulation transfer function of the primary $\mathrm{x}$-ray framing camera diagnostic results in insufficient exposure contrast but relative agreement with other determinations. The $\mathrm{x}$-ray intensity of the titanium backlighter driven by the 2.5-nsec linear ramp of the laser beams is described, and the relative intensity on film is compared to similar Nova experiments. The parallax effects of different length marker layers of high-opacity dichloropolystyrene is measured, resulting in the conclusion that the marker layer length should be matched to the laser drive illumination profile. 


\section{INTRODUCTION}

Studies of convergent hydrodynamics in cylindrical geometry are of interest both because of the excellent diagnostic access available in cylinders and because the results are well-matched to present two-dimensional computer codes. Previous experiments have used indirect drive on the Nova laser. ${ }^{1.2}$ The increased energy coupling efficiency available in directdrive and the excellent symmetry and smooth laser beams on the OMEGA facility allow cylinders of twice the diameter to be successfully imploded for hydrodynamic studies. Tubbs et al. ${ }^{3}$ have described the initial physics results from the first experimental campaign. This paper provides details about the experimental configuration, diagnostics, and backlighting.

\section{EXPERIMENTAL CONFIGURATION}

The 60 laser beams of the OMEGA facility ${ }^{4}$ are symmetrically

distributed around the target chamber in a stretched soccer-ball geometry ${ }^{5}$

with the beams located at the vertices of the hexagons and pentagons.

Between the beams are diagnostic ports, with six beams around "hexagonal" ports and 5 beams around "pentagonal" ports. Some diagnostic ports have diagnostic "ten-inch manipulators" or TIMs providing a standard, flexible, and adjustable interface for diagnostics such as framing cameras or spectrometers. The cylindrical axis of this experiment is chosen to align along the axis of two pentagonal ports on the OMEGA vacuum chamber. The Pent6-Pent7 axis is chosen because TIM4 in Pent6 allows imaging down the cylinder axis. Figure 1 shows an elevation of the target. A straight stalk (made of $150 \mu \mathrm{m}$ diameter carbon covered with boron) from the target insertion port in Pent 1 at the top of the vacuum vessel, 
when attached to the "far" end of the cylinder, does not intersect any of the drive laser beams (it would have intersected one oblique beam on the transverse backlighter that wasn't used anyway). Using a pentagonal port orientation makes the laser beams naturally divide up into 8 cones, 4 at each end of the cylinder. The angular centroids of the cones of laser beams are shown on the figure along with the location of their position of best focus. There are five laser beams azimuthally in cones 1 (used for backlighting) and 2 (pointed $720 \mu \mathrm{m}$ past the target center), and 10 beams in cones 3 and 4 (each pointed $110 \mu \mathrm{m}$ in front of target center). There are corresponding numbers of beams in the cones on the other side of the target. The beams all have distributed phase plates (DPPs) which create a gaussian intensity profile with $384 \mu \mathrm{m}$ (one-sigma) width. Two-dimensional smoothing by spectral dispersion (SSD) is used with $1.25 \times 1.75 \AA$ bandwidth.

There are two types of targets: axial backlit and transverse backlit (no target had both backlighters simultaneously). The target is glued onto the stalk with the cylinder axis at a nominal $63.4^{\circ}$ angle (metrologized to be within $1^{\circ}$ ). The axial backlighter is a $2-\mathrm{mm}$ diameter $6-\mu \mathrm{m}$ thick titanium foil with 1 mil of beryllium as a low-energy filter between it and the cylinder. The foil is cantilevered off the end of the cylinder with positioning within a few degrees of normal and within $10 \mu \mathrm{m}$. Five overlapping laser beams from cone 1 illuminate the backlighter from the side away from the target. A $180-\mu \mathrm{m}$ thick lead-doped ( $28 \%$ by weight) acrylic washer with OD of $1500 \mu \mathrm{m}$ and ID of $750 \mu \mathrm{m}$ is glued on the other end of the axial 
backlighter targets. A $50-\mu \mathrm{m}$ diameter tungsten fiber is glued pointing down from the end of the cylinder and metrologized with $\sim 10-\mu \mathrm{m}$ accuracy to provide $\mathrm{XYZ}$ location of the target in the viewing system. The transverse backlighter targets do not have an aperture, but have the 6- $\mu \mathrm{m}$ thick titanium foil backlighter (with no beryllium filter since it is hit on both sides by lasers) cantilevered off the main stalk in a location under a Hex port in a gap between drive beams. Four laser beams from each side (eight total, all but the two most oblique) overlap on the foil. A boron-coated carbon rotation fiber is glued $4 \mathrm{~mm}$ up the stalk and metrologized for its angle pointing at the $\mathrm{X}$-axis target viewing system (XTVS). The target is inserted, rotated using the rotation fiber (so the target is in the Pent6-Pent1-Pent7 plane), and then adjusted in the $\mathrm{X}$ and YTVS views using the alignment fiber. A template for the laser beams can then be electronically laid over the view as a check of the alignment. The construction of the target cylinder itself is described in the Figure 1 caption as well as in more detail in Tubbs et al. ${ }^{3}$ Figure 2 shows a photograph of an axial backlit target.

An advantage of a direct-drive target is the diagnostic access from all directions. The primary diagnostic is an $\mathrm{x}$-ray framing camera ${ }^{6}$ (designated XRFC4) in TIM4 in Pent 6 with an axial view at 12X magnification.

XRFC3 is used in TIM3 in Hex18 with a view $79.2^{\circ}$ from the cylinder axis with $6 \mathrm{X}$ magnification. This camera observes the transverse backlighter, and monitors self-emission from the target on all shots. XRFC1 (at 6X magnification) and a streaked spectroscopic camera (SSC1) point at the backlighter and monitor its emission. The array of six static pinhole 
cameras is also used to provide an overview of the time-integrated $\mathrm{x}$-ray emission.

\section{ESTIMATE OF MODULATION TRANSFER FUNCTION OF X-RAY FRAMING CAMERA}

An attempt was made to characterize the resolution of the $\mathrm{x}$-ray framing cameras on shots while the alignment and gain were being checked. Static targets (with no lasers hitting them) were fabricated of polystyrene $1000-\mu \mathrm{m}$ thick along the line of sight with a $50-\mu \mathrm{m}$ wide layer of dichloropolystyrene between two sides of plain $\mathrm{CH}$. This pr of $\mathrm{CH}$ corresponds to that expected during the actual cylinder implosion. One half of the target then had a 3- $\mu \mathrm{m}$ thick layer of gold covering it with a machined edge less than 1- $\mu \mathrm{m}$ wide (see Figure 3(a)). A shot was taken with the axial backlighter with all four strips of the microchannel plate (MCP) fired at the same time with the standard $4 \times 4$ pinhole array on XRFC4. Twelve of the resulting sixteen images (ignoring the four images in the extreme corners with maximum parallax and often cut-off by the edge of the MCP) had their central location determined by finding the center row of pixels at the gold edge and the middle of the columns of pixels at the cholorinated marker edges. The exposure of these twelve images were then summed [see Figure 3(b)]. The backlighter intensity clearly has a nearly circular, peaked profile. This profile is directly related to the gaussian profile of the DPP used on the beams coupled with the overlap of the five beams. The actual observed profile is offset due to slight camera and target misalignment (at [125,145] pixels rather than at the $[160,160]$ center) and is slightly elliptical (for 
reasons not understood) with a vertical sigma of $139 \mu \mathrm{m}$ and horizontal of $112 \mu \mathrm{m}$ (much less than the $384 \mu \mathrm{m}$ of the laser beam intensity spot from the overlapping of the slightly oblique $\left[21.4^{\circ}\right]$ beams and the nonlinear production of the $\mathrm{x}$ rays).

The intensity profile of the twelve summed images can be divided by a representation of the overall backlighter intensity profile, and then lineouts across the image taken. Figure 3(c) shows column lineouts taken on either side of the chlorinated marker (solid lines), and a row lineout taken across the non-gold region. Unfortunately, the 3- $\mu \mathrm{m}$ thickness of gold was not sufficient to make that region opaque. The "noise" level on the film is no higher than shown in the row lineout in the middle of the very opaque chlorinated layer. The MTF of very similar $\mathrm{x}$-ray framing cameras was determined by Robey et al. ${ }^{7}$ The expected response, including the relative transmission through the known target materials, is shown in Figure 3(c) as the dotted line. The MTF of this camera has been successfully measured by Smalyuk et al. ${ }^{8}$ The expected response is shown in Figure 3(c) as the dashed-dotted line. The transmission through the gold is more consistent with only a $2-\mu \mathrm{m}$ thick layer but that value is inconsistent with the known target fabrication. In short, the short-wavelength behavior is entirely consistent with known MTFs, and is dominated by the $8-\mu \mathrm{m}$ pinhole diameter. A similar target aligned along the transverse backlighter axis was tried but returned no useful data due to misalignment. 


\section{BACKLIGHTER INTENSITY}

Because all the 50 drive beams use the same pulse shape, and the backlighter beams must also use that pulse shape, the laser intensity on the backlighter is the same 2.5-nsec linear ramp as the drive. A worry was that a nonlinear relation of laser intensity and $\mathrm{x}$-ray brightness would limit the time duration of usable $x$-ray emission for a given gain setting of the XRFC. The SSC1 in TIM2 in Hex7 is used to monitor the time behavior of the Helium-like titanium radiation from the backlighter. No absolute timing fiducial was available on the streak record. A sweep speed of $120 \mathrm{ps} / \mathrm{mm}$ is assumed and the time determined from the point of sharp decrease of the $\mathrm{x}$-ray emission at the end of the laser pulse. On different days of operation the five laser beams incident on the backlighter were delayed different durations from the main drive pulse: $0.6 \mathrm{nsec}, 1.1 \mathrm{nsec}$, and $0.8 \mathrm{nsec}$. Figure 4(a) shows the backlighter laser pulse shape for beam $\mathbf{4 2}$ for all shots with analyzable axial radiography. Figure 4(b) shows a lineout through the streak record for those shots with streak data (some shots had bad wedge data or the SSC was being used to monitor chlorine line emission instead). The observed $\mathrm{x}$-ray intensity is delayed from the laser pulse drive. On all the axial backlighter shots the peak exposure on the film down the axis of the cylinder was determined. Because the gain varies along the MCP as the pulse travels across the strip only the data from the second frame of each strip is tabulated. The gain differences between strips $^{9}$ was calibrated to be a minor $(<10 \%)$ effect. On some frames the self-emission from the axial stagnation shock dominates the emission and the peak backlighter exposure must be estimated from the gaussian profile away from the shock. Some shots used $10-\mu \mathrm{m}$ pinholes and some $8 \mu \mathrm{m}$; the exposure is normalized by the pinhole area. The exposure on the film is 
only approximate in its absolute calibration as the wedge used is not absolute. Figure 4(c) shows this normalized exposure, which has also been divided by the total backlighter laser energy (a few percent effect), plotted vs time. The transmission late in time is reduced as the foam core of the target compresses. Data from one shot (11635) at $3.2-3.5 \mathrm{nsec}$ is quite high because eight drive beams failed to fire on that shot, delaying the implosion and keeping the foam core still relatively transparent at that time. Shots on the last day (with the backlighter beams delayed $0.8 \mathrm{nsec}$ ) had a more "quadratic" shape to the pulse. This apparently led to increased x-ray emission at the time of sharp laser power increase. In any case, a period of about $1.5 \mathrm{nsec}$ is available when the film exposure is in a reasonable dynamic range for radiography even with this linear ramp laser pulse.

The absolute emission of the backlighter cannot be estimated because of uncertainty in the wedge on the film and the gain of the XRFC system. Nevertheless, relative statements about the brightness of the backlighter can be made that are useful to others planning OMEGA experiments. Using PDS digitization of the film and wedge and an assumed peak exposure of the LLE-provided wedge of $2 \mathrm{ergs} / \mathrm{cm}^{2}$ the exposure on the film is $6 \times 10^{-3} \mathrm{ergs} / \mathrm{cm}^{2}$ through the $\mathrm{CH}$ of the MTF target (Figure 3) and 16 times larger or $10^{-1} \mathrm{ergs} / \mathrm{cm}^{2}$ through the uncompressed foam of an imploding cylinder. The transmission of $\mathrm{x}$ rays through the target and 6- $-\mu \mathrm{m}$ titanium filter and 6 mils of beryllium at $4.5 \mathrm{keV}$ of the titanium backlighter is $6 \%$ for the $\mathrm{CH}$ of the MTF target and 8 times greater for the $2000 \mu \mathrm{m}$ of uncompressed foam. The extra factor of two in exposure in the implosion does not come from self-emission, which provides an exposure of only $\sim 10^{-2} \mathrm{ergs} / \mathrm{cm}^{2}$ as determined by a shot done without backlighter. All this is 
happening during a FWHM time interval of $80 \mathrm{psec}$ in the pulse forming module of the camera. This can be compared to the average (in space) peak (in time) laser intensity on the backlighter from $1.9 \mathrm{~kJ}$ of beams in a 2.5 nsec linear ramp with the DPPs of $2 \times 10^{14} \mathrm{~W} / \mathrm{cm}^{2}$. Cylindrical implosion experiments have been done at the Nova laser using the similar FXI-1 camera (with $\sim 60 \%$ of the gain of XRFC4 and a 90-psec FWHM pulse forming module) using the same filtering but only a $690-\mu \mathrm{m}$ length of uncompressed $100-\mathrm{mg} / \mathrm{cc} \mathrm{CH}$ foam (so $\sim 13 \%$ more transmissive). For this Nova data (shot 28022716 frame $3 \mathrm{~b}$ ) there is $0.7 \mathrm{ergs} / \mathrm{cm}^{2}$ density on the film through $10-\mu \mathrm{m}$ pinholes. The backlighter is illuminated by $3.3 \mathrm{~kJ}$ of $2 \omega$ light on a spot $700 \mu \mathrm{m}$ in diameter in a $2-\mathrm{nsec}$ square pulse for an average intensity of $4.3 \times 10^{14} \mathrm{~W} / \mathrm{cm}^{2}$. Assuming the approximate wedge correction is accurate for the OMEGA data, and folding in all factors, the factor of two higher intensity on Nova results in perhaps a factor of 5 greater exposure.

\section{PARALLAX EFFECTS FROM DIFFERENT LENGTH MARKER LAYERS}

One of the issues in the initial experiments ${ }^{3}$ was the length of the dichloropolystyrene marker layer (see Figure 1). Targets with either "long" ( $500 \mu \mathrm{m}$, matched to the illumination pattern) or "short" $(250 \mu \mathrm{m})$ marker layers were shot both unperturbed and with perturbations. Images from two similar shots can then be compared to assess the effects of parallax from the length of the marker. Shot 11614 (long marker) and 11615 (short marker) were compared in frame $4 \mathrm{a}$ at $1.67 \mathrm{nsec}$ and an outer marker radius of $340-358 \mu \mathrm{m}$. The effective apparent thickness of a unperturbed 
marker layer is $22 \mu \mathrm{m}$ (long) vs $25 \mu \mathrm{m}$ (short) compared to a calculated effective thickness of a thin cylinder observed from that frame of $16 \mu \mathrm{m}$ (long) or $8 \mu \mathrm{m}$ (short). Significant problems in the axial hydrodynamics were observed when the marker layer was shorter than the illumination pattern ${ }^{3}$, causing the actual increase in effective observed thickness with short marker layers of less parallax. Future targets will all use long markers matched to the illumination.

\section{ACKNOWLEDGMENTS}

The authors thank the operations staff of the OMEGA laser for their outstanding support. Pete Gobby, Harry Bush, Bob Day, Veronica Gomez, Joyce Moore, Gerry Rivera, and John Townsend did a great job fabricating and metrologizing these very complicated targets. We thank Dana Hargrove and "Nino" Landen (both of LLNL) for useful comments and help with the details of the backlighting and framing cameras. This work was performed under the auspices of the U.S. Department of Energy by the Los Alamos National Laboratory under contract No. W-7405-Eng36. 


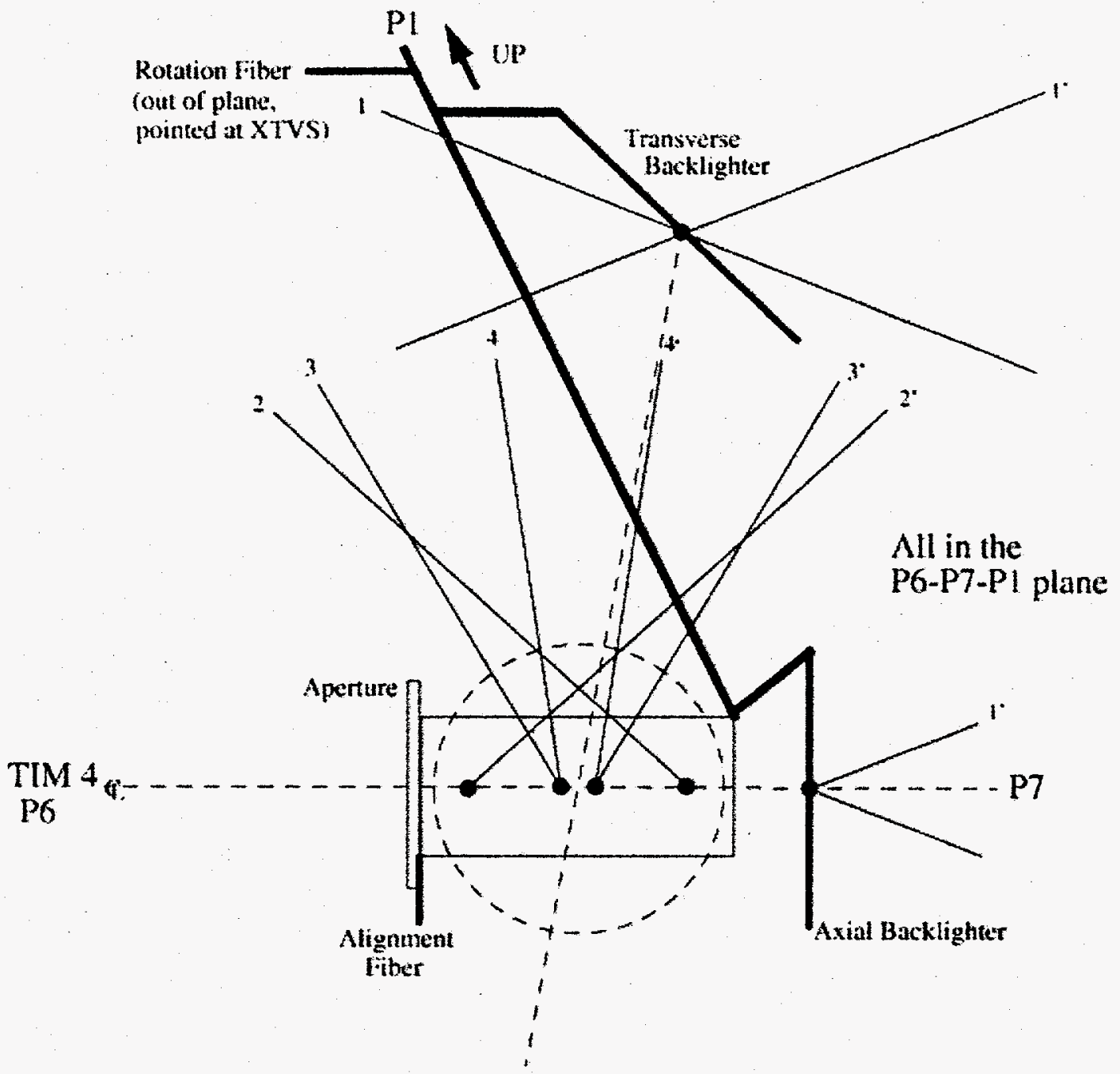

TIM 3

$\mathrm{H} 18$

Figure 1: Elevation view of the direct drive cylinder target design and mounting. The thin lines represent the centerlines of the laser beam cones (see text). The dotted circle is the outline of a 4-mm diameter spherical target used for pointing confirmation of the beams. The $2250 \mu \mathrm{m}$ long cylinder has a $20 \mu \mathrm{m}$ thick $\mathrm{CH}$ shell and a $2000 \mu \mathrm{m}$ long $60 \mathrm{mg} / \mathrm{cc}$ CH foam insert. In the central region of the cylinder the shell is $16 \mu \mathrm{m}$ of $\mathrm{CH}$ over a $4 \mu \mathrm{m}$ thick $\mathrm{C}_{8} \mathrm{H}_{6} \mathrm{Cl}_{2}$ (dichloropolystyrene) marker region that is either $500 \mu \mathrm{m}$ or $250 \mu \mathrm{m}$ long. 


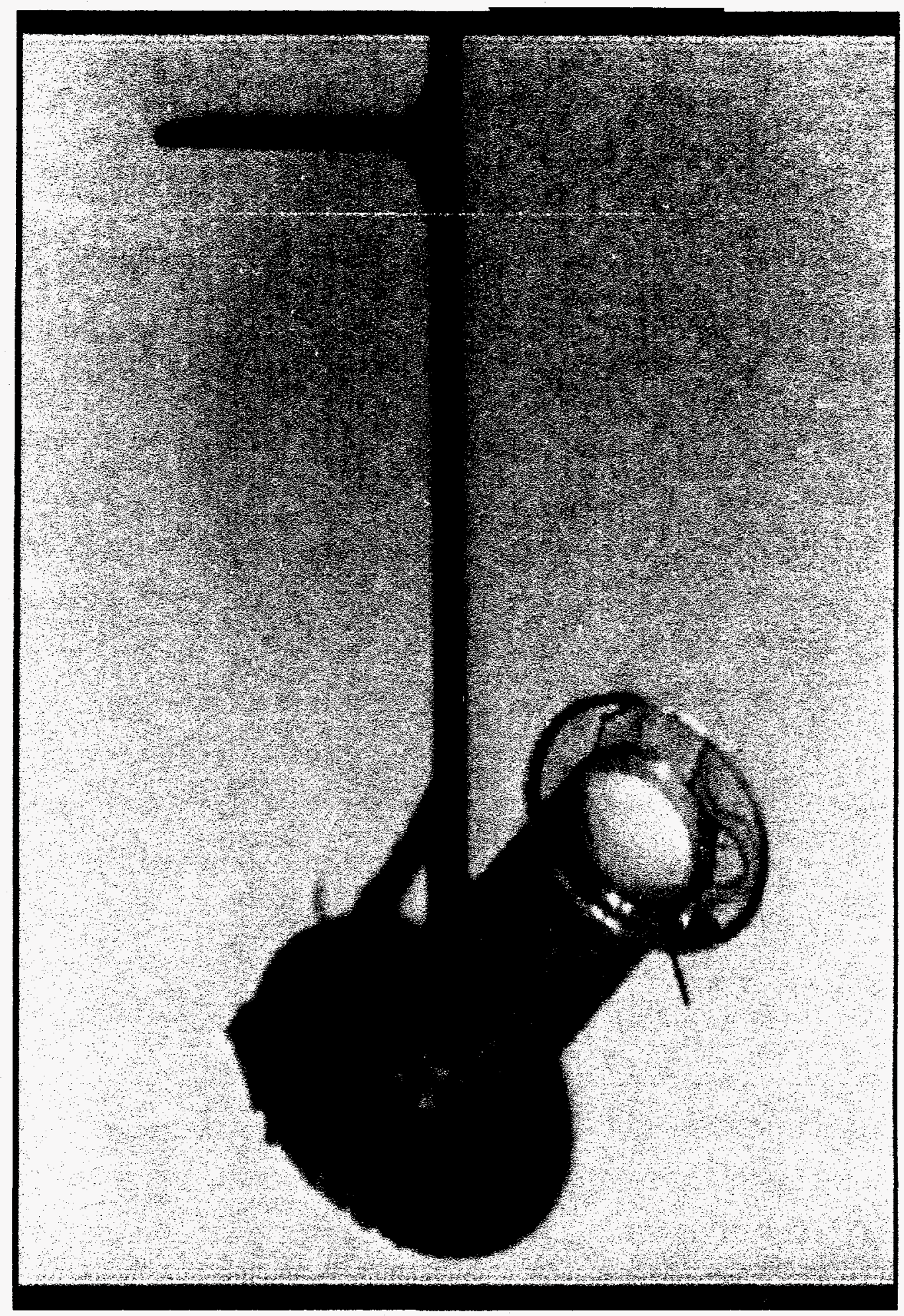

Figure 2: Photo of a direct drive cylinder target with axial backlighter. Rotation and alignment fibers can be seen, as can the leaded-acrylic washer aperture. 


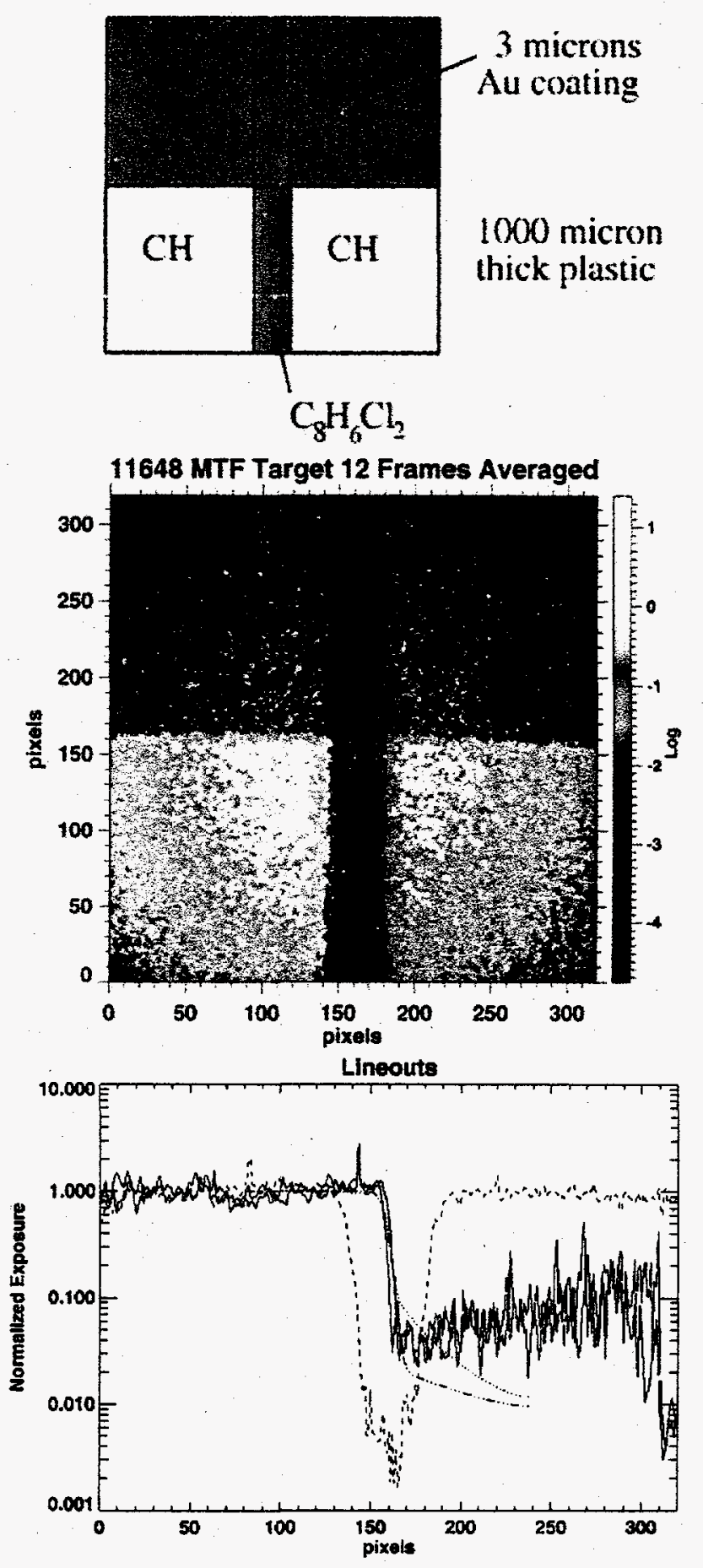

Figure 3: Results from attempt to measure the Modulation Transfer Function (MTF) of the $x$ ray framing camera XRFC4. (a) Diagram showing layout of target looking towards backlighter. (b) Exposure image from twelve frames summed (see text). The orientation is the same as in the diagram in (a). (c) Lineouts of the density, both vertical (solid lines) and horizontally across the dichloropolystyrene layer (dashed line). The dotted curve is a fit to this data using the MTF of Robey et al. ${ }^{7}$ while the dashed-dotted curve is a fit using the MTF of Smalyuk et al. ${ }^{8}$ 

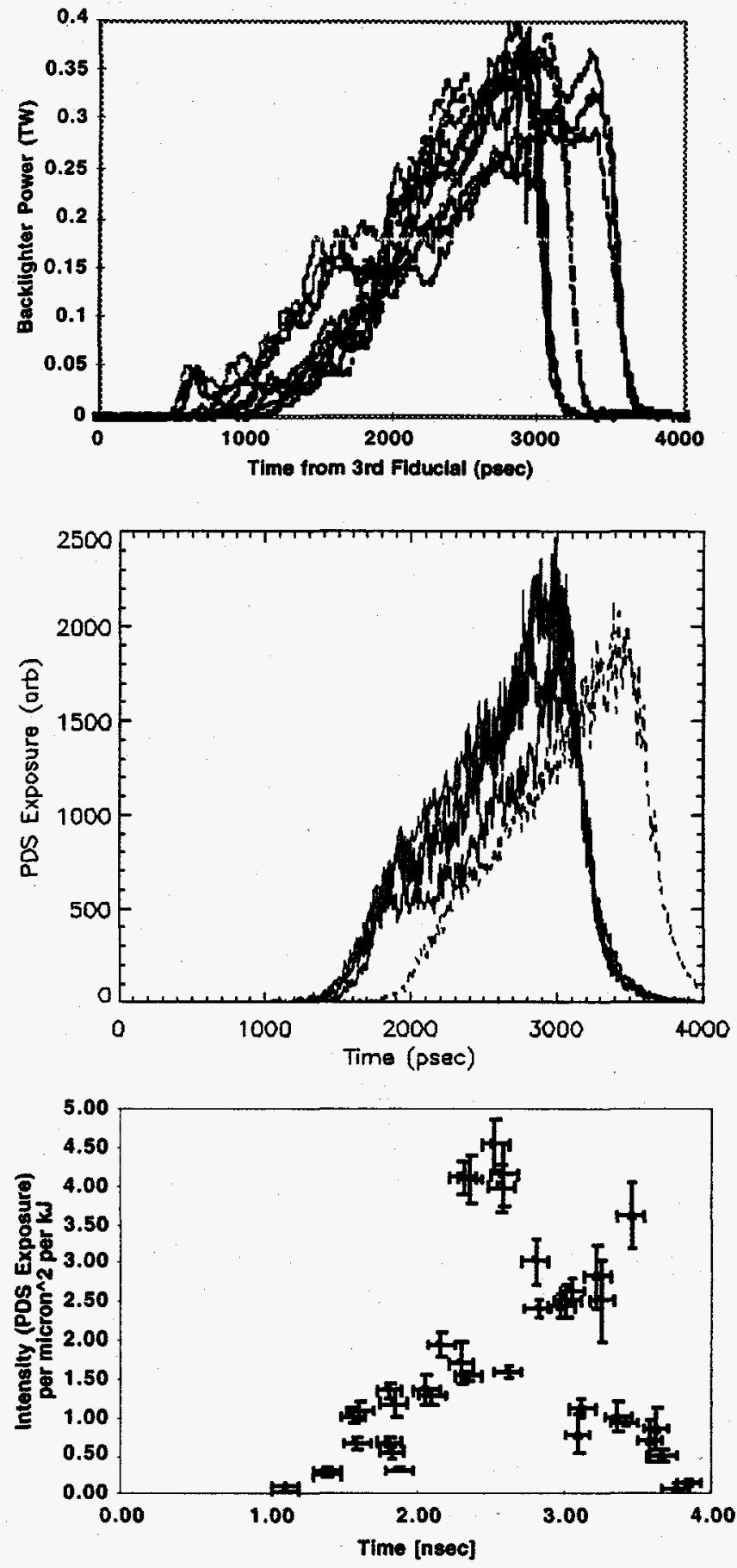

Figure 4: Backlighter intensity compared to laser pulse shape and timing. (a) Laser power from beam 42 (one of five beams on backlighter). The solid lines are from four shots with the backlighter pulse ending at 3.1 nsec; the dashed lines from three shots with the backlighter ending at 3.6 nsec; and the thick dashed lines from three shots with the backlighter ending at 3.3 nsec and having a consistently different shape. (b) Lineouts in time through the heliumlike titanium lines of the SSC. (c) Film exposure down the axis of the cylinder vs time. The film exposure has been normalized to pinhole area and also backlighter laser energy. The different symbols represent different times of the backlighter ending: solid circles (3.1 nsec), the open triangles (3.6 $\mathrm{nsec}$ ), and open squares ( $3.3 \mathrm{nsec}$ ). 


\section{REFERENCES}

${ }^{1}$ Warren W. Hsing and Nelson M. Hoffman, "Measurement of feedthrough and instability growth in radiation-driven cylindrical implosions," Phys. Rev. Lett. 78 (1997) 3876.

${ }^{2}$ W. W. Hsing, Cris W. Barnes, J. B. Beck, N. Hoffman, D. Galmiche, A. Richard, J. Edwards, P. Graham, S. Rothman, and B. Thomas, "Rayleigh-Taylor instability evolution in ablatively driven cylindrical implosions," Phys. Plasmas 4 (1997) 1832.

${ }^{3}$ David L. Tubbs, Cris W. Barnes, J. B. Beck, N. M. Hoffman, J. A. Oertel, R. G. Watt, T. R. Boehly, D. Bradley, and J. P. Knauer, "Direct Drive Cylindrical Implosion Experiments: Simulation and Data," presented at the XXV European Conference on Laser Interactions in Matter, Formia, Italy, 1998, (submitted to Lasers and Particle Beams).

${ }^{4}$ T. R. Boehly et al., "Initial performance results of the OMEGA laser system," Optics Communications 133 (1997) 495.

${ }^{5}$ R. S. Craxton, editor, "OMEGA Upgrade Preliminary Design," Laboratory for Laser Energetics Report DOE/DP 40200-101, University of Rochester (1989).

${ }^{6}$ D. K. Bradley et al., "High-speed gated x-ray imaging for ICF target experiments," Rev. Sci. Instrum. 63 (1992) 4813.

${ }^{7}$ H. F. Robey, K. S. Budil, and B. A. Remington, "Spatial resolution of gated x-ray pinhole cameras," Rev. Sci. Instrum. 68 (1997) 792.

${ }^{8}$ V. A. Smalyuk, T. R. Boehly, D. K. Bradley, J. P. Knauer, and D. D. Meyerhofer, "Characterization of an X-ray Radiographic System Used to Measure the Evolution of Broadband Imprint in Laser-Driven Planar Targets," this conference (1998).

${ }^{9}$ Memo by Dana Hargrove, "FXI Relative Gain Measurements," L-24646-01, October 15, 1997. 